RFP-643

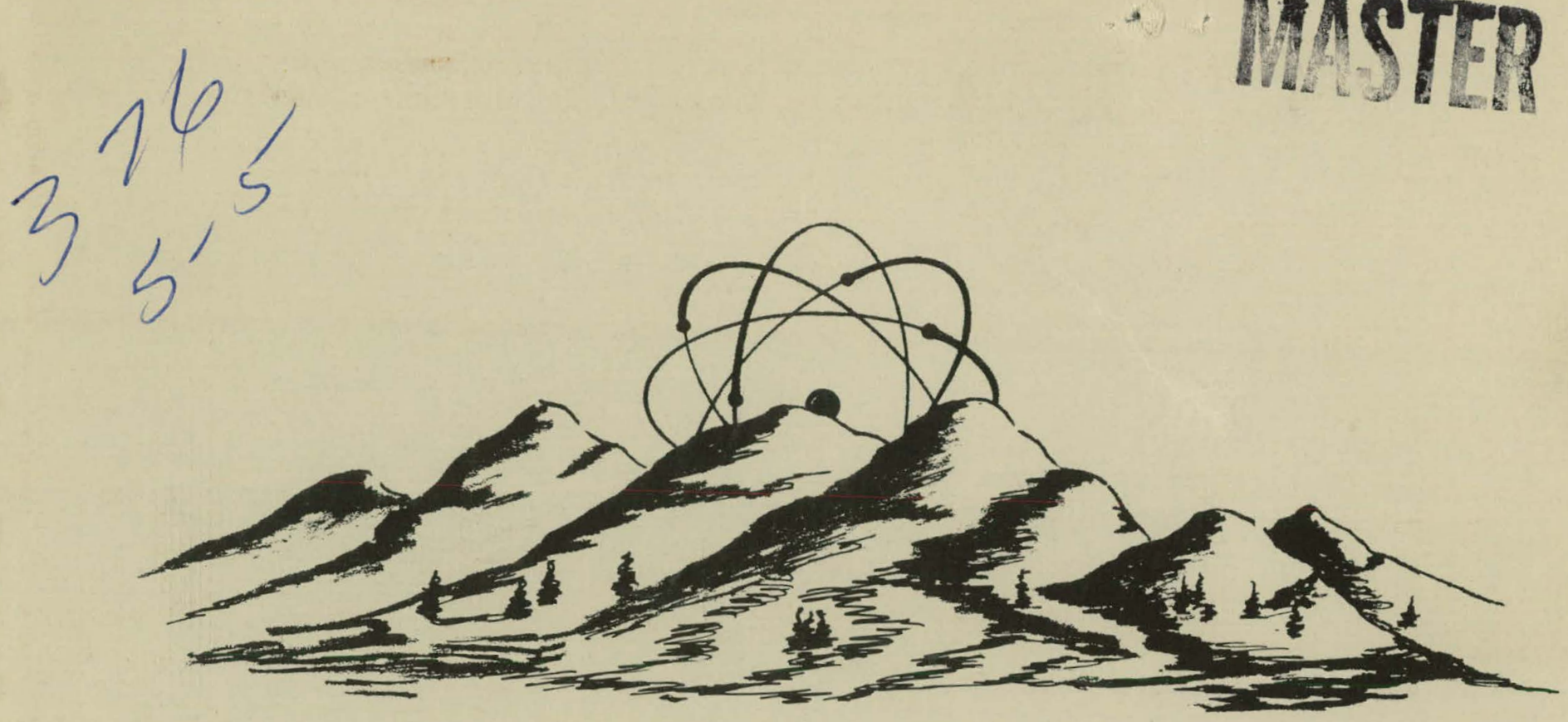

LOW-ENERGY ELECTRON DIFFRACTION STUDY OF THE (100) PLANE OF A TUNGSTEN SINGLE CRYSTAL

by

R. O. Adams

RELEASED FOR ANNOUNCEMENT IN NUCLEAR SCIENCE ABSTRACTS

THE DOW CHEMICAL COMPANY ROCKY FLATS DIVISION P. O. BOX 888

GOLDEN, COLORADO 80401

U.S. ATOMIC ENERGY COMMISSION CONTRACT AT (29-1)-1106 


\section{DISCLAIMER}

This report was prepared as an account of work sponsored by an agency of the United States Government. Neither the United States Government nor any agency Thereof, nor any of their employees, makes any warranty, express or implied, or assumes any legal liability or responsibility for the accuracy, completeness, or usefulness of any information, apparatus, product, or process disclosed, or represents that its use would not infringe privately owned rights. Reference herein to any specific commercial product, process, or service by trade name, trademark, manufacturer, or otherwise does not necessarily constitute or imply its endorsement, recommendation, or favoring by the United States Government or any agency thereof. The views and opinions of authors expressed herein do not necessarily state or reflect those of the United States Government or any agency thereof. 


\section{DISCLAIMER}

Portions of this document may be illegible in electronic image products. Images are produced from the best available original document. 


\section{LEG AL NOTICE}

This report was prepared as an account of Government sponsored work. Neither the United States, nor the Commission, nor any person acting on behalf of the Commission:

A. Makes any warranty or representation, expressed or implied, with respect to the accuracy, completeness, or usefulness of the information contained in this report, or that the use of any information, apparatus, method, or process disclosed in this report may not infringe privately owned rights; or

B. Assumes any liabilities with respect to the use of, or for damages resulting from the use of any information, apparatus, method, or process disclosed in this report.

As used in the above, "person acting on behalf of the Commission" includes any employee or contractor of the Commission, or employee of such contractor, to the extent that such employee or contractor of the Commission, or employee of such contractor prepares, disseminates, or provides access to, any information pursuant to his employment or contract with the Commission, or his employment with such contractor.

Printed in USA. Price $\$ 3$. Available from the Clearinghouse for Federal Scientific and Technical Information, National Bureau of Standards, U. S. Department of Commerce, Springfield, Virginia 


\title{
LOW-ENERGY ELECTRON DIFFRACTION STUDY OF THE
}

(100) PLANE OF A TUNGSTEN SINGLE CRYSTAL

\author{
by
}

R. O. Adams

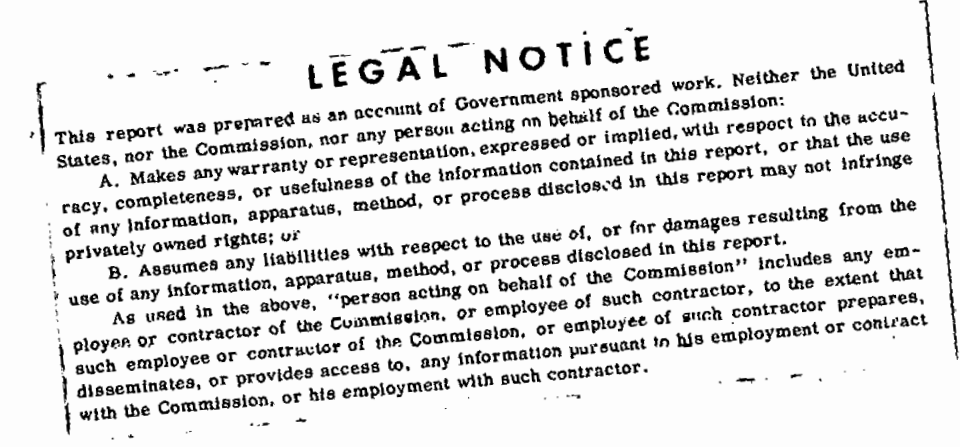

THE DOW CHEMICAL COMPANY

ROCKY HLA'S DIVISION

P. O. BOX 888

GOLDEN, COLORADO 80401

U.S. ATOMIC ENERGY COMMISSION

CONTRACT AT(29-1)-1100 


\title{
ABSTRACT
}

\author{
A survey of the low-energy electron diffraction \\ technique is given. Diffraction patterns associated \\ with a clean tungsten (100) surface are given \\ and analyzed. It is found that subsurface layers \\ contribute significantly to the diffraction \\ pattern obtained from this plane even at low \\ electrón energies. Chemisorption of nitrogen, \\ oxygen, hydrogen and carbon monoxide are \\ followed by observation of changes in the \\ diffraction pattern. No rearrangement of the \\ tungsten surface due to the chemisorbed gases \\ is observed.
}


TABLE OF CONTENTS

ABSTRACT . . . . . . . . . . . . . . . . . . . . .

SUMMARY AND CONCLUSIONS . . . . . . . . . . . . . . 1

INTRODUCTION . • . . . . . . . . . . . . . . . . . 2

METHOD OF ANALYSIS . . . . . . . . . . . . . . . . 4

EXPERIMENTAL

Apparatus . . . . . . . . . . . . . . . . 14

Procedure . . . . . . . . . . . . . . . . . . 17

RESULTS AND DISCUSSION

Cleaning of the Surface and

the Clean Surface Patterns . . . . . . . . 19

Nitrogen Chemisorption . . . . . . . . . . . 27

Hydrogen Chemisorption . . . . . . . . . . 34

Carbon Monoxide Chemisorption . . . . . . 36

Oxygen Chemisorption . . . . . . . . . . . 38

LITERATURE REFERENCES . . . . . . . . . . . . . . . 45 
RFP-643 


\section{SUMMARY AND CONCLUSIONS}

The low-energy electron diffraction pattern associated with a clean tungsten (100) surface has been observed and analyzed. It was determined that the pattern does not originate from the surface layer of atoms alone. In the (100) direction the second atomic layer is a significant contributor to the basic diffraction pattern.

Observation of the chemisorption of nitrogen on the surface was done by following the changes in the diffraction pattern as the nitrogen was adsorbed. It was observed that nitrogen chemisorbs in two distinct states. One layer forms where there is one nitrogen atom for each two tungsten surface atoms. After this layer is complete, an additional layer forms by filling the remaining sites on the tungsten surface until there is one nitrogen atom for each tungsten surface atom.

No distinctive patterns were observed for hydrogen and carbon monoxide chemisorption. The gas atoms in both cases fill all the available interstitial sites on the tungsten surface, forming no preferred pattern while doing so. Very little, if any, additional hydrogen or carbon monoxide is adsorbed after the initial layer is formed.

Oxygen was observed to chemisorb by rapidly filling all available interstitial surface sites. An additional layer is then adsorbed on top of the first. The second layer is loosely bound and is easily removed by a-mild heating of the crystal. 


\section{INTRODUCTION}

Low energy electron diffraction (LEED) provides a means whereby the arrangement of atoms at the surface of a material may be indirectly observed. The LEED technique has been used primarily on metals and semiconductors, but there has been limited application to insulators. The basic requirement on the material to be studied is that it be a single crystal and that the surface used be a known plane of the crystal.

A monoenergetic electron beam with energy between 0 and $150 \mathrm{~V}$ is normally used in LEED. Electrons in this energy range have very little penetration into the material being studied, consequently, the electron beam is principally diffracted by the surface layer of atoms. The diffraction pattern is therefore indicative of a two dimensional lattice; however, there is some penetration and it cannot be ignored completely. The penetration will depend not only on the energy of the electrons but also on the nature of the particular crystal face exposed to the electron beam. At higher energies there is more penetration than at lower energles. There is also more penetration in the more open lattice directions than in the more tightly packed lattice directions.

LEED data cannot at present be interpreted with the precision found in $x$-ray or high-energy electron diffraction for a number of reasons. Atomic scattering factors are not precisely known. Absorption of the incident and diffracted beams necessitates large corrections which are only qualitatively understood. Corrections due to the internal potential cannot be accurately made and the spread in electron beam energy, approximately $0.3 \mathrm{~V}$, is significant at low energies. 
The factors above substantially reduce the precision with which the atomic positions can be determined. However, by using known crystal planes and by having some knowledge of the nature of the material of interest, the problem is not impossible. 


\section{METHOD OF ANALYSIS}

Consider a beam of electrons striking at normal incidence a row of atoms with repetition distance d (See Figure 1). Each atom is assumed to be a source of radiation of wavelength equal to that associated with the incident beam of electrons. The diffraction condition for a beam of low energy electrons can be found by considering the secondary radiation from adjacent atoms. Examination of Figure 1 shows that the path difference between $O A M$ and $O^{\prime} \mathrm{BM}^{\prime}$ is $A C$, which is equal to $d \sin \theta$. For the two beams to interfere constructively, the path difference must be an integral multiple of the wavelength associated with the beam of electrons. The diffraction condition, or as it is sometimes called, the Laue condition, is

$$
\mathrm{n} \lambda=\mathrm{d} \sin \theta
$$

$\lambda$ is the wavelength associated with the electron beam given in angstroms by $\lambda=\sqrt{\frac{150}{V}}$, if $\mathrm{V}$ is the accelerating potential in volts, $\mathrm{n}$ is an integer and $\theta$ is the angle between the incident and diffracted beams. It is a relatively simple matter to make an extension to two dimensiors, but in doing this it must be remembered that the atoms radiate in all directions.

To simplify the discussion of the diffraction patterns, a brief explanation of surface structure nomenclature will be helpful. The two dimensional lattice is described analogously to the three dimensional lattice used in $x$-ray diffraction. The rows and columns in the two dimensional lattice are identified by a set of two dimensional Miller indices just as are the planes in the three dimensional lattice. A coordinate system is arbitrarily chosen on the lattice, and the rows and columns are defined in terms of their axial intercepts. Figure 2 is a representation of the (100) plane 


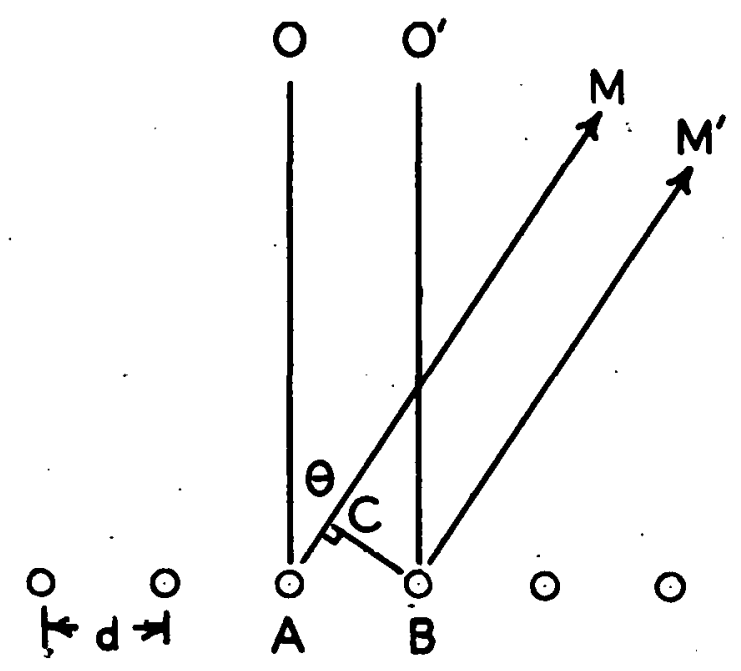

Figure 1. DIAGRAM ILLUSTRATING THE ORIGIN OF THE ONE DIMENSIONAL LAUE CONDITION. THE CIRCLES REPRESENT ROWS OF ATOMS ON THE SURFACE. THE ORIGIN OF THE ELECTRON BEAM IS AT $00^{\prime}$ : 


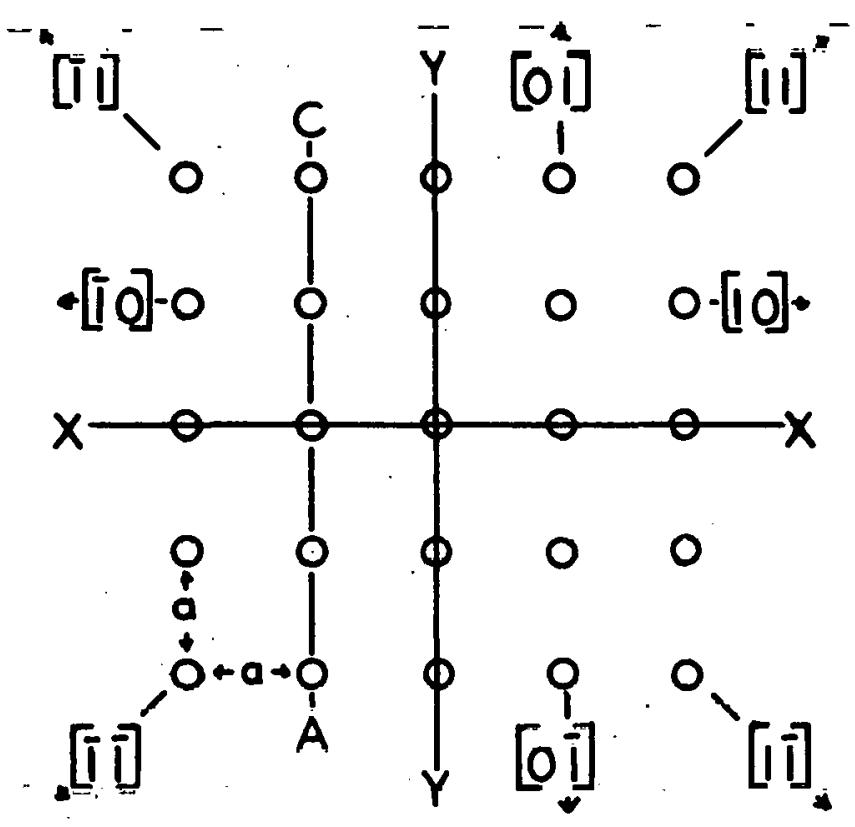

Figure 2. SCHEMATIC REPRESENTATION OF A (100) FACE OF A BCC CRYSTAL. THE CIRCLES REPRESENT THE SURFACE ATOMS. THE SURFACE LATTICE DIRECTIONS OR AZIMUTHS ARE INDICATED BY THE SQUARE BRACKETS. 
of a (bcc) crystal, and shows how the coordinate system was chosen for this discussion. (The small circles indicate the positions of the atomic centers and not the size of the atoms relative to the crystal lattice.)

It is customary in discussing diffraction patterns to use the term azimuth. An azimuth is an arbitrarily chosen direction in relation to the crystal structure. An azimuth is defined as the direction normal to a row of atoms and is designated by the reciprocals of the axes intercepts of the rows of atoms analogous to the Miller indices. For example, the [10] azimuth is normal to the $\mathrm{Y}$ axis in the positive $\mathrm{X}$ direction. Since the four azimuths normal to the $X$ and $Y$ axes are all equivalent in our case because of the square lattice, these will be referred to as the [10] azimuths. Similarly, the four $45^{\circ}$ diagonals will be referred to as the [11] azimuths.

Now to determine the Laue condition in two dimensions. The atoms in the surface layer of a crystal form rows with uniform spacings. In the azimuth associated with a row of atoms, the radiation from all the atoms in the row is in phase. Therefore, the diffraction in a given azimuth is due to interference between the rows of atoms perpendicular to the azimuth. For example, referring to Figure 2, any diffraction effects in the [10] and [10] azimuths will be due to interference in the radiation in all rows parallel to row AC. A diffraction spot will occur in these azimuths for those angles $\theta$ measured in these azimuths between the incident and diffracted beams which satisfy equation (1). The same will be true in all azimuths, i.e., a diffraction spot will occur when equation (1) is atisfied using the proper interrow spacing and measuring the angle in the proper azimuth: 
Analysis with equation (1) above will at best give only the size of the surface unit cell. In order to say anything at all about the positions of atoms in the unit cell, the intensities of the diffraction spots must be considered. This is the point at which the detailed analysis of LEED patterns breaks down. To calculate the intensities of diffraction spots, the atomic scattering factors for the atoms involved must be known. The atomic scattering factors are unknown for low energy electrons; however, with a few assumptions and approximations, some useful calculations can be made.

Consider a row of atoms with repetition distance a. A beam of low energy electrons strikes the atoms at normal incidence. Each atom is assumed to radiate with an amplitude $f_{i} \exp \left(j \varphi_{i}\right)$, where $f_{i}$ is the atomic scattering factor for an atom of type $i$ and $\varphi_{i}$ is a phase angle. If the atoms in the row were all of the same type, the amplitude of the diffracted wave would be $f N$, where $N$ is the number of atoms in the row. There is no phase term because all like atoms radiate in phase in the direction given by the Laue condition, $n \lambda=a \sin \theta_{x}$.

Now suppose that there are two different atoms per unit cell, atom 1 at the origin and atom 2 located at a distance $x_{2}<a$ from the origin (atom B in Figure 3). All the atoms of this type will radiate in phase in the direction given by the Laue condition. We are interested in determining the contribution of these atoms to the intensity of the diffraction spot. The amplitude of the radiation scattered from the 


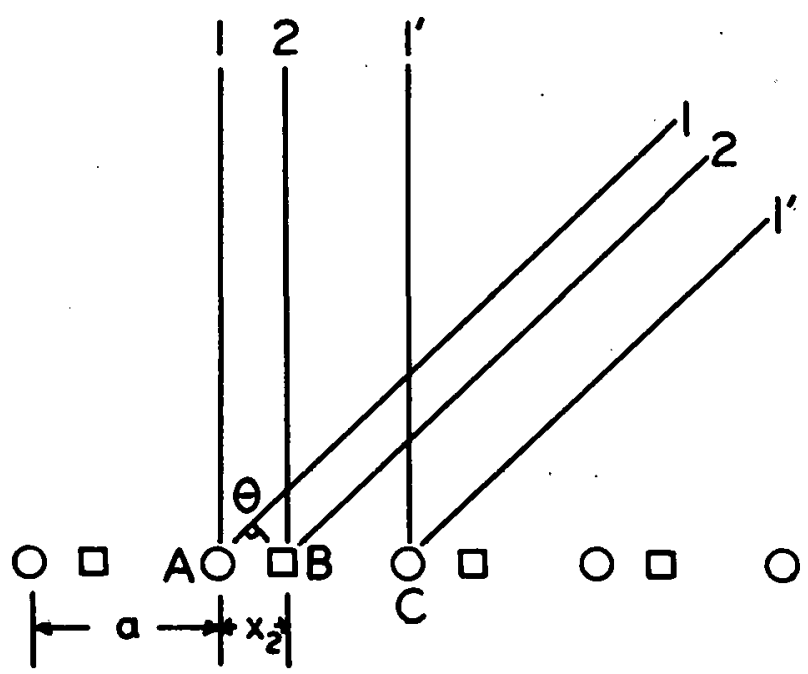

Figure 3. DIAGRAM ILLUSTRATING THE ORIGIN OF THE ONE DIMENSIONAL LAUE CONDITION FOR TWO UNLIKE ATOMS PER UNIT CELL. 
second atom, i.e., the atom located at $B$, will be $f_{2} \exp \left(j \varphi_{2}\right)$, where $f_{2}$ is the atomic scattering factor of the type 2 atom and $\varphi_{2}$ is the phase angle between the radiation from atom 1 and atom 2 . The problem is to find this phase angle.

It is easily seen in Figure 3 that the path difference between ray $I$ and ray 2 is $x_{p} \sin \theta$. From the Laue condition we know that $\sin \theta_{x}=n \lambda / / a$. Thus, the path difference $\delta$ is

$$
\delta=\frac{\mathrm{x}_{2} \mathrm{n} \lambda}{\mathrm{a}}
$$

The phase difference $\varphi_{2}$ is given by

$$
\varphi_{2}=\frac{2 \pi}{\lambda} \cdot \delta
$$

therefore, in our case;

$$
\varphi_{2}-\frac{2 \pi x_{2} n}{a}
$$

The total amplitude is the sum of the contributions from atoms 1 and 2 , and if there are $\mathrm{N}$ unit cells, this is

$$
A_{n} \approx\left[f_{1}+f_{2} \exp \left(j 2 \pi \mu_{2} n\right)\right] N=F_{n} N
$$

where $\mu_{i d}=x_{2} / 2$. The intonoity is thus given

$$
I_{n} \approx\left|F_{n}\right|^{2} N^{2}=\left[f_{1}^{2}+2 f_{1} f_{a} \cos 2 \pi \mu_{a} n+f_{2}^{a}\right] N^{2}
$$

$F_{n}$ is called the structure factor. In equation (6) we can see some of 
the difficulty in making detailed analysis of LEED patterns. $f_{1}, f_{2}$, and $\mu_{2}$ are all unknowns.

The exterision to a plane $\mathrm{NxM}$ array of unit cells introduces the second Laue condition, $k \lambda=b . \sin \theta_{y}$. The amplitude of the radiation from a two atom unit cell in this case would be

$$
A_{n k} \approx f_{1} \exp \left[2 \pi j\left(n \mu_{1}+k \nu_{1}\right)\right]+f_{2} \exp \left[2 \pi j\left(n \mu_{2}+k \nu_{2}\right)\right] \text {. }
$$

This can be written in a more general and more compact manner thus :

$$
A_{n k} \approx \Sigma f_{i} \exp \left[2 \pi j\left(n \mu_{i}+k \nu_{i}\right)\right]
$$

where $\nu_{i}=y_{i / b}$. Since there are NxM unit cells, the intensity maximums are

$$
I_{n k} \approx\left|F_{n k}\right|^{2} N^{2} M^{2}=\left|\Sigma f_{i} \exp \left[2 \pi j\left(n \mu_{i}+k \nu_{i}\right)\right]\right|^{2} N^{2} M^{2}
$$

It is observed that the quantity $\left|F_{n k}\right|^{2}$ dominates low-energy electron diffraction, although the proportionality is altered in various ways. An array of beams can generally be found which can be related to the substrate lattice of the crystal plane with which we are working. Note in equation. (9) that, for a plane array, $\left|\mathrm{F}_{n k}\right|^{2}$ is independent of wavelength if the $f_{i}$ 's are independent of wavelength. This is not expected to be the case.

In making an analysis it is found that the above must be extended in everal ways. Extra spots are often observed and the intensities depend 
on voltage in ways which cannot be explained by the plane-grating assumption given above. The plane-grating assumption could be approached by putting a dense and planar array of heavy atoms on a light atom substrate. This has been done with iodine on a silicon (111) surface. ${ }^{1}$ It was found that the plane-grating formula was nearly correct but that there were effects due to the atoms in layers below the first which were strong even at moderate voltages.

Let us consider the effect on the intensity of adding one or more planes of atoms at distances $z_{i}$ below the first. It will be shown. later that this is an important consideration for the tungsten (100) plane.

Assume that the surface atoms form a square array so that the periodicities in the $x$ and $y$ directions are identical. Scattered radiation from an atom i. at $\mu_{i} \nu_{i}{ }_{i}$ has an amplitude, for normal incldence,

$$
A_{i} \approx f_{i} \exp \left[n \mu_{i}+k v_{i}+z_{i}(I+\cos \theta) / \lambda\right]
$$

The structure factor term in the intensity expression for this case has the form

$$
\begin{aligned}
\left|F_{n k l}\right|^{2}= & \left(\sum f_{i} \cos 2 \pi\left[z_{i}(1+\cos \theta) / \lambda+n \mu_{i}+k \nu_{i}\right]\right)^{2} \\
& +\left(\sum f_{i} \sin 2 \pi\left[z_{i}(1+\cos \theta) / \lambda+n \mu_{i}+k \nu_{i}\right]\right)^{2} .
\end{aligned}
$$

Equation (11) shows that the atoms at different levels modulate the intensity function with a change in wavelength.

LEED experiments have shown that surface atoms of clean surfaces are ofter extensively rearranged. ${ }^{1}, 2,3$ It has also been shown that adsorbed atoms 
may occupy sites not entirely equivalent to those of the base crystal and may cause rearrangements of underlying atoms.4,5 Analysis of surface diffraction is often an effort to analyze two structures simultaneously with the simplifying assumptions that they are in register in the $x$ and $y$ directions and that the structure of the underlying crystal is known. 


\section{EXPERIMENTAL}

\section{Apparatus}

Although the analysis of LEED patterns is complex, the apparatus with which to obtain them is relatively simple. A monoenergetic beam of electrons with which to bombard the crystal face under study and a method by which the diffracted beams can be observed are the basic requirements. Since LEED studies are made to investigate phenomena associated with clean surfaces or surfaces under known conditions, they must be carried out in ultra-high vacuum.

The LEED apparatus used in these experiments is a commercially available unit.6 A schematic diagram of the LEED vacuum system is shown in Figure 4. The system is constructed of non-magnetic stainless steel and is completely bakeable. It is pumped by a 140 liter/second getter-ion type pump and is capable of maintaining pressures in the low $10^{-10}$ torr range. The crystal holder, the electron beam source, and the diffracted beam display are contained in the diffraction chamber.

The LEED equipment utilizes the post-acceleration technique described by Ehrenberg. ${ }^{7}$ In this technique the back-scattered electrons are accelerated through a large potential difference onto a fluorescent screen. The diffraction_pattern is then observed as an array of bright spots. The electron gun, its associated electronics, and the geometry of the system have been described by Scheibner, et al.,$^{8}$ by Germer and Hartman, 9 and by Lander, et a1.10

Figure 5 shows a schematic cross section representation of the geometrical arrangement of electron gun, crystal, and screen. Thermionic electrons are 


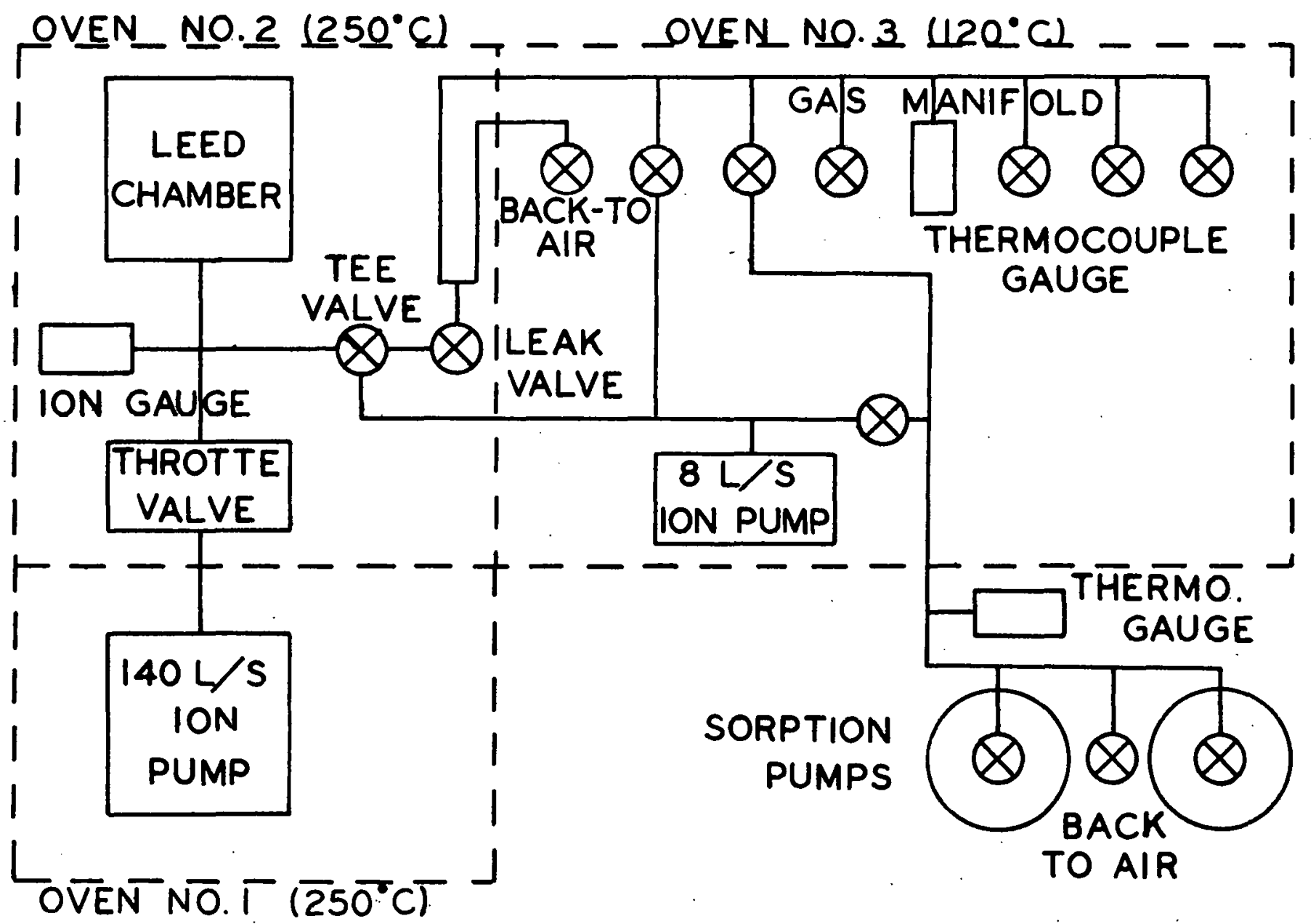

Figure 4. SCHEMATIC DIAGRAM OF THE LEED VACUUM SYSTEM. 


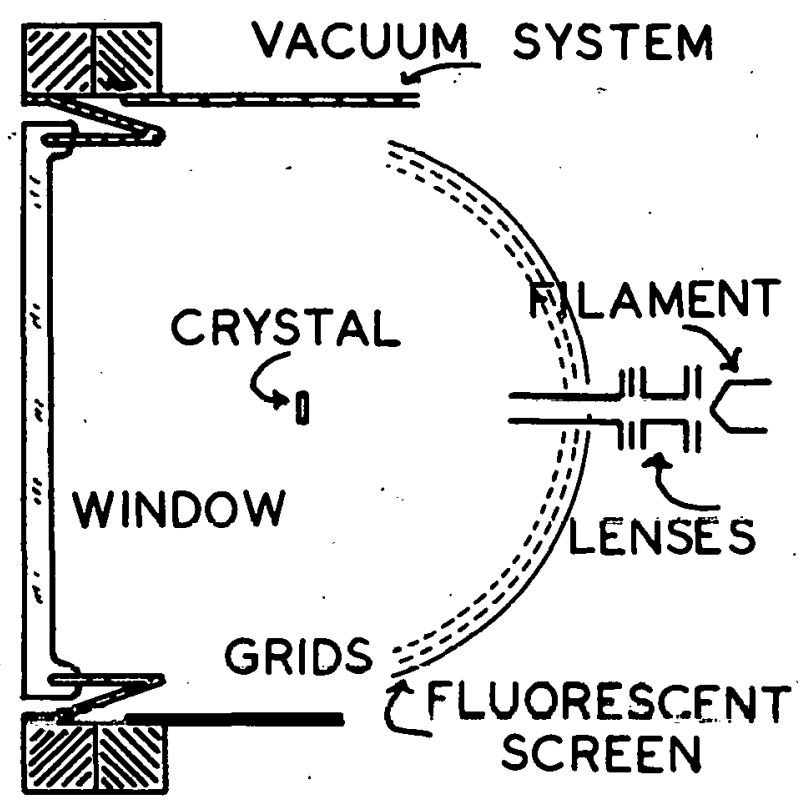

Figure 5. SCHEMATIC CROSS SECTION DIAGRAM OF THE DIFFRACTION CHAMBER. 
emitted from the low temperature cathode. The electron gun forms a beam of electrons $1 \mathrm{~mm}$ in diameter at the target which has a dispersion in energy of 0.2 volts. The gun protrudes through the center of the spherical fluorescent screen. At the center of curvature of the screen, the crystal is placed with the face to be studied exposed to the electron beam.

Between the crystal and the fluorescent screen, close to and concentric with the screen, are two fine mesh grids. The grid on the target side serves to provide a region of constant electric field about the crystal. This preserves the trajectories of the scattered electrons so that little if any distortion occurs in the diffraction pattern. The grid next to the fluorescent screen is usually operated at cathode potential and thus acts as a filter, allowing only the elastically scattered electrons to strike the screen. A high potential is applied between the fluorescent screen and this second grid. The electrons that penetrate the grid are thus accelerated into the screen with sufficient energy to excite the phosphor, giving the bright spot. Since the second grid is very close to the screen, very little distortion in the electron path occurs.

The single crystal used in these experiments was a ribbon $0.003-i n c h$ thick, 1/4-inch wide, and 1-inch long. The (100) plane was exposed on the 1/4-inch face. It was mounted by molybdenum spring clips to the crystal manipulator, which allows $180^{\circ}$ of rotation about a vertical axis and translation in three directions. Cleaning of the crystal could be accomplished by conductive heating or ion bombardment.

\section{$\underline{\text { Procedure }}$}

Since we are interested in studying the chemisorption of various gases on a clean tungsten surface, the only procedure involves obtaining and 
RFP -643

maintaining a clean surface. This means that residual pressures in the ultra-high vacuum range must be obtained.

Pressures in the $10^{-10}$ torr range are obtained after a 20-hour bake-out at $250^{\circ} \mathrm{C}$. This is followed by degassing of the ion gauge and the electron gun. Specific treatment of the crystal will be discussed later in the results.

Gases used in the adsorption experiments were reagent grade pure gases in one-liter Pyrex flasks. They were admitted to the diffraction chamber through a manually operated leak valve.

Photographs of the diffraction pattern were taken with a Polaroid camera using film with an ASA rating of 3000 . 


\section{RESULTS AND DISCUSSION}

\section{Cleaning of the Surface and the Clean Surface Patterns}

The tungsten crystal used in these experiments was obtained commercially in the form described above. ${ }^{1}$ The crystal was grown by the zone refining method, then cut, ground, and polished to the desired orientation and size. Table I lists the maximum impurity content of the crystal.

\section{Table I}

THE MAXIMUM IMPURITY CONTENT OF VARIOUS

MATERIALS IN THE TUNGSTEN CRYSTAL

$\begin{array}{ll}\text { Oxygen } & 1.9 \mathrm{ppm} \\ \text { Hydrogen } & 0.3 \mathrm{ppm} \\ \text { Carbon } & 0.0 \mathrm{ppm} \\ \text { Nitrogen } & 5.0 \mathrm{ppm} \\ \text { Iron } & 0.0 \mathrm{ppm} \\ \text { Molybdenum } & 0.0 \mathrm{ppm} \\ \text { Niobium } & 0.0 \mathrm{ppm}\end{array}$

There is provision in the apparatus for three methods of cleaning the crystal surface: (1) sputtering, (2) ion bombardment and (3) Joule heating. Any one of these methods will produce a clean surface; however, neither sputtering nor ion bombardment alone are satisfactory for LEED studies. Sputtering and ion bombardment both destroyed the surface structure so that no diffraction pattern was obtainable. It was necessary to anneal the crystal after sputtering or ion bombardment to reinstate the surface crystal structure. Because of this need for annealing, Joule heating was used in all these experiments.

rigure 6 shows clean surface diffraction patterns at several electron energies. If these patterns are compared to patterns determined by 


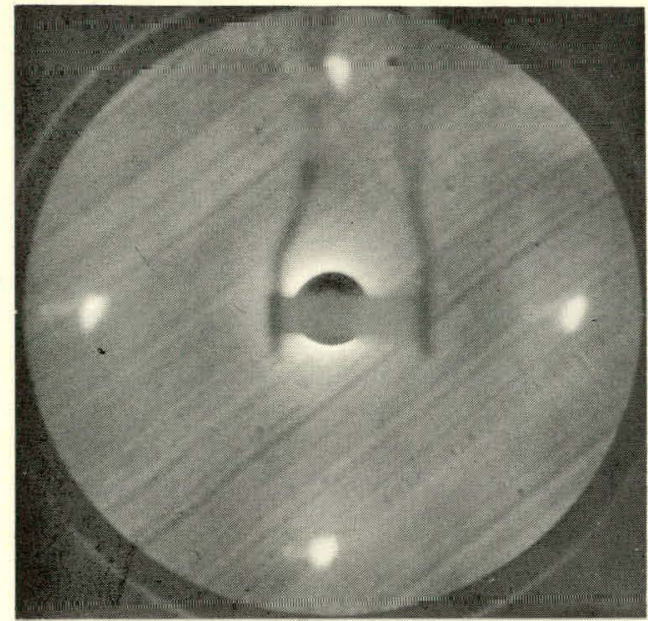

(a)

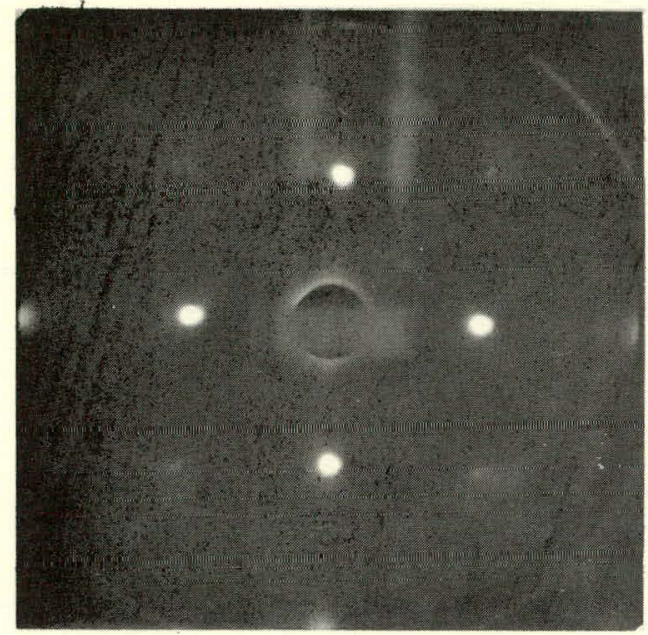

(c)

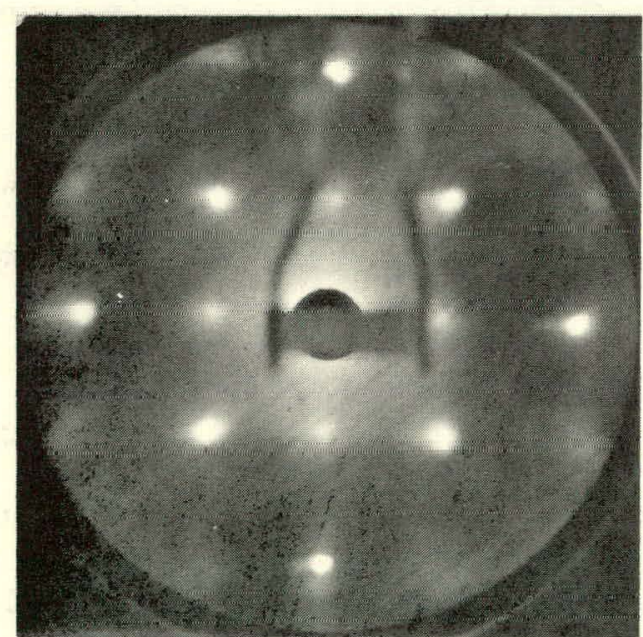

(e)

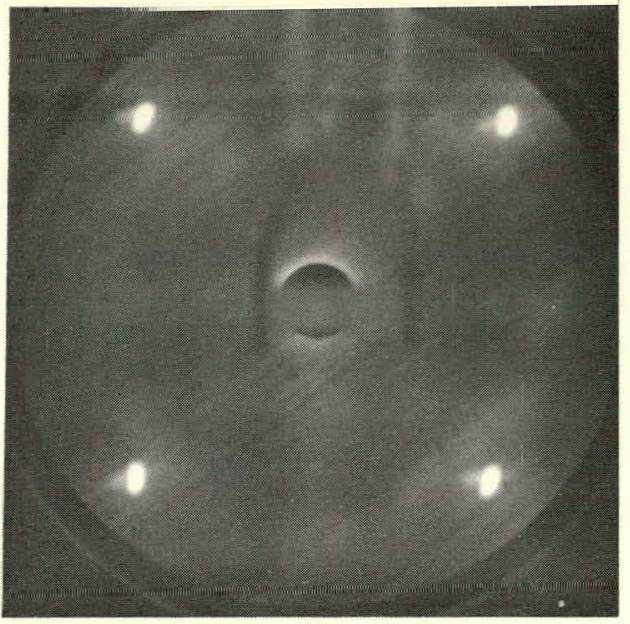

(b)

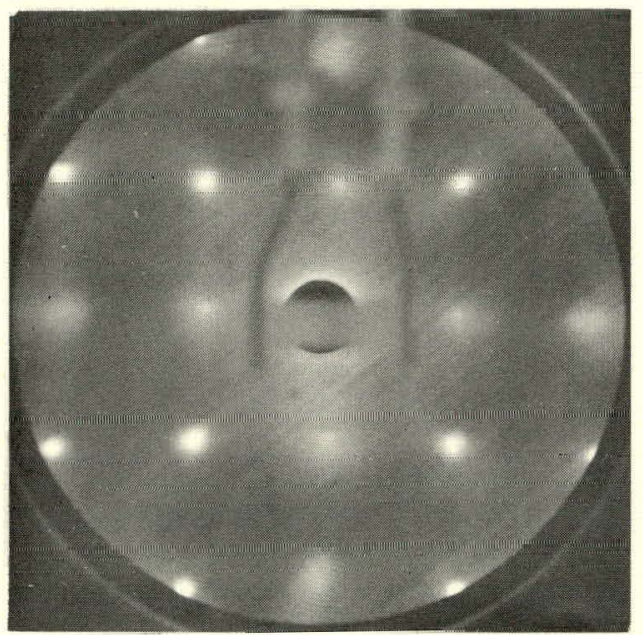

(d)

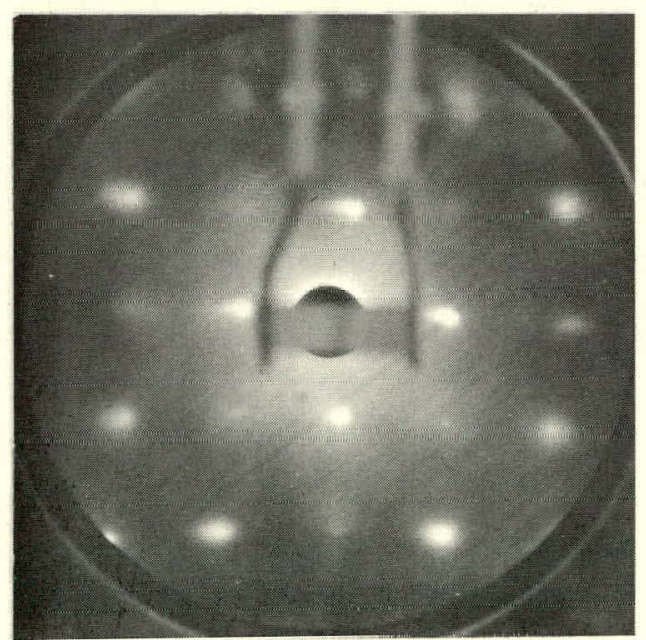

(f)

Figure 6. DIFFRACTION PATTERNS FROM A CLEAN TUNGSTEN (100) SURFACE FOR VARIOUS ELECTRON ENERGIES: (a) $44 \mathrm{~V}$, (b) $77 \mathrm{~V}$, (c) $105 \mathrm{~V}$, (d) $140 \mathrm{~V}$, (e) $162 \mathrm{~V}$ and (f) $200 \mathrm{~V}$ 
$\mathrm{n} \lambda=\mathrm{d} \sin \theta$ for a two dimensional square lattice, some differences will be noticed. The two dimensional Laue condition for a square array predicts a pattern of eight equally intense spots arranged in a square with spots at each corner of the square and at each midpoint of each side. The patterns displayed in Figure 6 show that this is not observed.

Tungsten has a body centered cubic (bcc) crystal structure. A (100) plane of this structure is fairly open, i.e., a large portion of the atoms in the lower levels are exposed. Figure 7 is a marble model of the (100) plane of a tungsten crystal. One notices that the atoms in the second layer are quite visible through the atoms of the top layer. Thus, it is probable that the second layer is a significant contributor to the LEED pattern of this type of surface.

In analyzing the diffraction patterns in Figure 6, it was assumed that the bulk crystal spacings extend to the surface. Thus, the spacing between the rows and columns in the [10] azimuths is equal to the interatomic distance of $3.1647 \AA$, and the distance between the rows in the [11] azimuths is $(\sqrt{2} / 2) a_{\circ}$ or $2.2374 \AA$. Using these values for $d$ in the Laue condition, $\lambda=\mathrm{d} \sin \theta ; \theta$ can be found in the appropriate azimuths or directions. By this method it is determined that the four bright spots in the $44 \mathrm{~V}$ and $105 \mathrm{~V}$ patterns, Figures $6 \mathrm{a}$ and $6 \mathrm{c}$ respectively, are due to diffraction in the [10] directions. The $77 \mathrm{~V}$ pattern, Figure $6 \mathrm{~b}$, is diffraction in the [11] directions. In the other three patterns in Figure 6 (140V, 162V, and 200V), the spots forming the corners of the square are due to diffraction in the -11] directions, and those at the midpoints of the sides are due to diffractions in the [10] directions. 
RFP-643

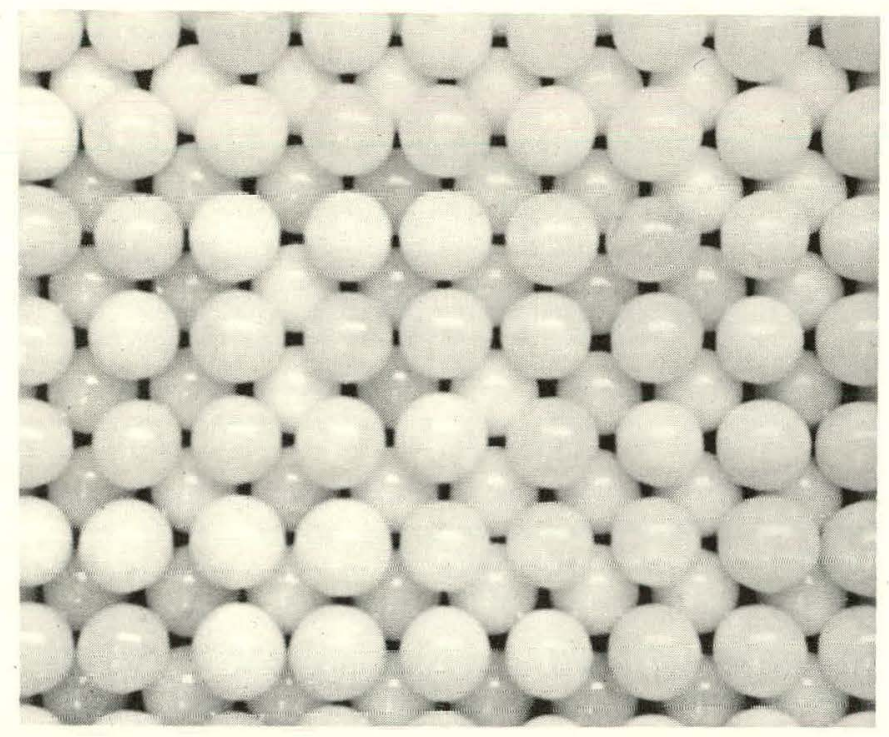

Figure 7. MARBLE MODEL OF A CLEAN TUNGSTEN (100) SURFACE. 
It was mentioned above that a basic eight spot diffraction pattern should be expected from the. [10] rows and columns and the [11] diagonals. Since this is not what is observed, the causes for the observed deviations must be determined. The observed patterns can be explained if it is assumed that the atoms in the second layer are strong diffracting points and contribute significantly to the overall pattern. To determine the contribution to the diffraction pattern of the second layer it is necessary to establish the phase difference between the electrons scattered from the two layers. This phase relationship can be established by determining the path difference between the electrons scattered from the top layer and those scattered from the second layer.

As an example, consider the diffraction of $77 \mathrm{~V}$ electrons (Figure $6 \mathrm{~b}$ ) in the [10] directions. Figure 8 is a cross section of what the incident electrons see in the [10] directions. The atoms in both layers are separated by a distance $d$ and the two layers are separated by a distance.z. The rows of atoms in the second layer are located midway between the rows of atoms in the top layer. The diffraction spot occurs at an angle $\theta$ in the four [10] directions as determined by $\lambda=d \sin \theta$.

Consider two coherent electron beams leaving the source AA' $^{\prime}$ and traveling the paths $A B C$ and $A^{\prime} B^{\prime} C^{\prime}$. The phase relationship between these two beams at the observation point $\mathrm{CC}^{\prime}$ will be determined by the path difference between $A B C$ and $A^{\prime} B^{\prime} C^{\prime}$ and its relationship to the wavelength of the electron beam. The electrons traveling the two paths are in phase along $A B$ and $A^{\prime} M$. In order to arrive at $C^{\prime}$ in phase, the electrons at $P$ must be 


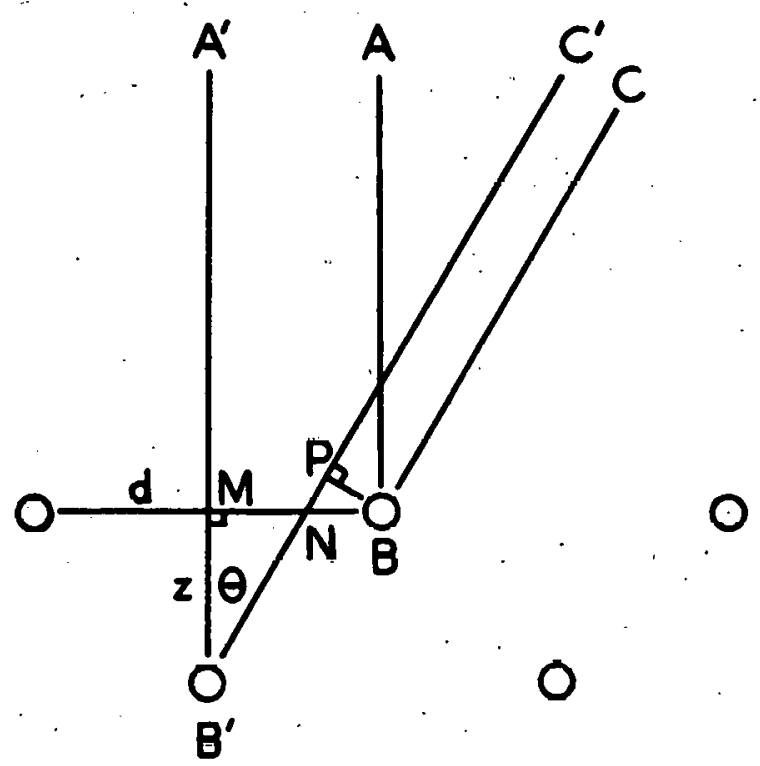

Figure 8. DIAGRAM ILLUSTRATING THE INTERFERENCE IN THE [10.] DIRECTIONS DUE TO THE SECOND LAYER. 
in phase with those at B. Thus, the path difference is MB'P. By simple geometry this can be expressed in terms of the known quantities $d, z$, and $\theta$ as,

$$
\text { Path Difference }=z\left(1+\frac{1}{\operatorname{Cos} \theta}\right)+\left(\frac{d}{2}-z \tan \theta\right) \sin \theta .
$$

In the $77 \mathrm{~V}$ case, $\lambda=1.396 \AA$ and the Laue condition predicts a diffraction spot in the [10] directions, where $\mathrm{d}=3.1647 \AA$, at $\theta=26^{\circ} 10^{\prime}$. Solving equation (12) for this case, a path difference of 2.6 times the wavelength is found. Thus, the electrons scattered from the second layer are nearly 180 degrees out of phase with those scattered from the top layer. Therefore, at best, a very dim diffraction spot should occur. None is observed.

For the [11] directions the geometry is slightly different. Figure 9 shows a cross section of the two layers for the [11] case. In this case the rows of atoms in the two rows are below each other. Referring to Figure 9, it is easily seen that the path difference is $B B^{\prime} M$. In terms of the known quantities $d, z$, and $\theta$, the path difference $P D$ is given by

$$
\mathrm{PD}=\mathrm{z}(1+\operatorname{Cos} \theta) .
$$

The Laue condition for $77 \mathrm{~V}$ electrons, $\lambda=1.396 \AA$, predicts diffraction spots at $38^{\circ} 36^{\prime}$ in the [11] directions. 'Solution of equation (13) yields a path difference of $2 \lambda$. Thus, in the [11] directions, electrons scattered from the top and second layers are in phase and should produce a bright spot in the predicted location. This is observed. 


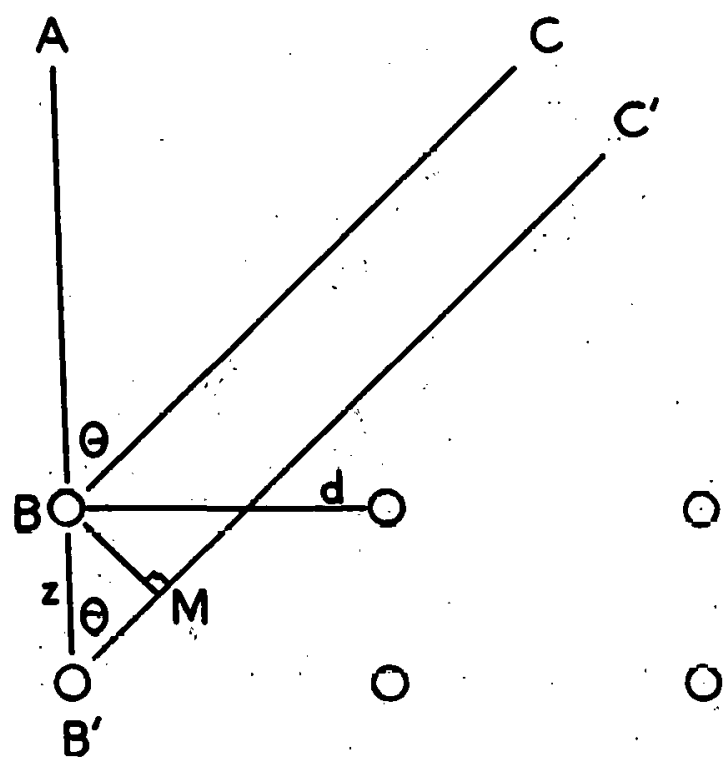

Figure 9. DIAGRAM ILLUSTRATING THE INTERFERENCE IN THE [11] DIRECTIONS DUE TO THE SECOND LAYER. 
Similar analysis predicts the bright [10] spots and very dim [11] spots in the $44 \mathrm{~V}$ and $105 \mathrm{~V}$ cases. At the higher energies ( $140 \mathrm{~V}$ and $\mathrm{up}$ ) the electrons penetrate farther into the lattice and the even deeper lying layers contribute to the diffraction pattern. Complete analysis of these cases would require solution of equation (11) which cannot be solved completely because of lack of information. However, a simple analysis with equations (12) and (13) gives adequate results.

Nitrogen Chemisorption

Nitrogen was allowed to adsorb on a clean surface and changes in the diffraction pattern due to the adsorbed gas were observed. The crystal surface was cleaned by periodically flashing it to $2100^{\circ} \mathrm{C}$ at pressures in the low $10^{-9}$ torr range. When the crystal could be heated for 10 seconds with no resulting increase in pressure, it was assumed clean. Following this treatment, the clean surface diffraction pattern shown in Figure 10a was observed. After the crystal had been cleaned and had cooled to room temperature, the throttling valve was closed and pure nitrogen was admitted to the diffraction chamber through a leak valve. The pressure in the chamber was raised to various values from $5 \times 10^{-9}$ torr to $5 \times 10^{-6}$ torr and held constant at the selected value sufficiently long to assure monolayer coverage. The diffraction patterns were photographed periodically.

Figure 10 shows the changes in the $77 \mathrm{~V}$ diffraction pattern as the nitrogen is adsorbed on the tungsten surface. After an exposure of $5 \times 10^{-6}$ torr-sec, the pattern shown in Figure 10b was established. At this point the four diffuse spots in the [11] directions, forming the inner square, 


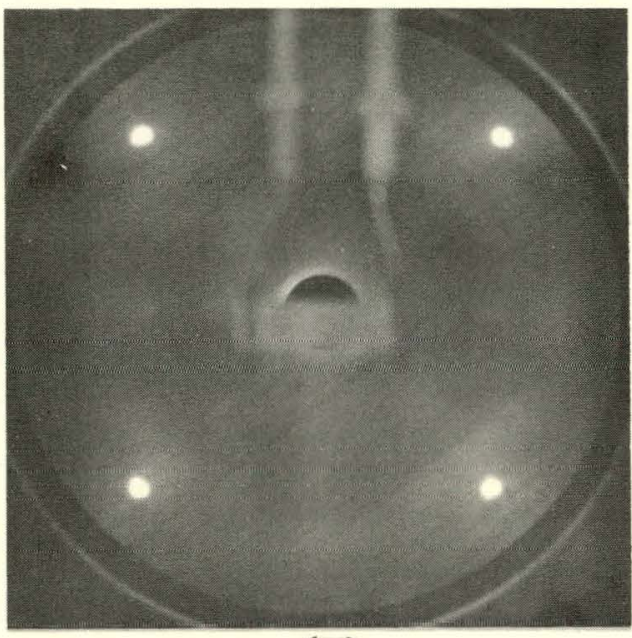

(a)

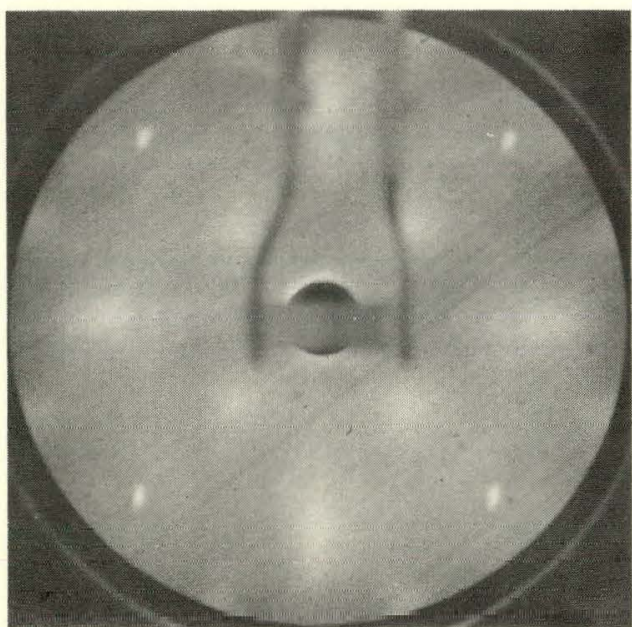

(c)

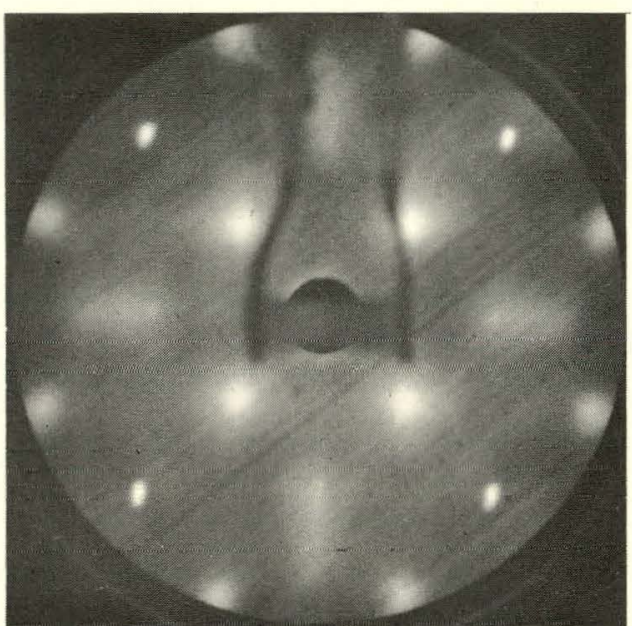

(b)

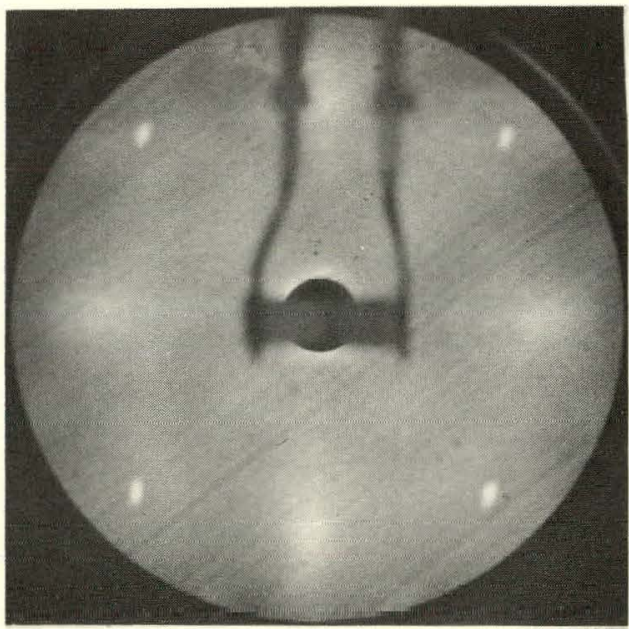

(d)

Figure 10. DIFFRACTION PATTERNS AT 77V SHOWING NITROGEN ADSORPTION ON A TUNGSTEN (100) SURFACE: (a) CLEAN SURFACE PATTERN, (b) PATTERN AFTER AN EXPOSURE OF $5 \times 10^{-6}$ TORR-SEC, (c) PATTERN AFTER A $7.5 \times 10^{-5}$ TORR-SEC EXPOSURE AND (d) PATTERN AFTER A $5 \times 10^{-4}$ TORR-SEC EXPOSURE 
reached their maximum intensity. Also, at this point it was necessary to reduce the size of the leak in order to maintain a constant pressure. This latter condition would indicate a decrease in the rate of adsorption of the crystal. In addition to the square pattern, dim diffuse spots began to appear in the [10] directions at the midpoints of the sides of the square formed by the clean surface pattern.

As the tungsten surface was exposed further to the nitrogen, additional modifications in the diffraction pattern occurred. These modifications occurred slowly. The overall intensity of the background increased gradually, the inner square pattern slowly dimmed and finally disappeared, and the diffuse spots in the [10] directions became brighter. The progress of these modifications can be seen in Figures 10c and 10d. Figure $10 \mathrm{c}$ shows the diffraction pattern after a $7.5 \times 10^{-5}$ torr-sec exposure. The intensity decrease of all spots in the [11] directions can be seen, as well as the increase in background intensity and the intensity increase of the [10] spots. After an exposure of $5 \times 10^{-4}$ torr-sec, the patterns had the appearance of that shown in Figure 10d. The inner square had disappeared at this point. Further exposure to nitrogen did not further alter the diffraction pattern.

Applying the Laue condition $\lambda=\mathrm{d} \sin \theta$ to the inner square structure in the diffraction pattern in Figure $10 \mathrm{~b}$, it is found that $\mathrm{d}=4.62 \AA$. The spacing between the rows in the [11] directions is $a_{\circ} \sqrt{2} / 2$, or $2.2374 \AA$, which is roughly half of this d value. Thus, the inner square structure probably arises from diffracting rows separated by twice the crystal lattice 
spacing in the [11] directions. An arrangement of nitrogen atoms which would satisfy this condition is shown in Figure 11. This arrangement will be called the half-monolayer coverage.

Before going further, it should be established that the patterns observed upon nitrogen adsorption are due to diffraction from nitrogen atoms on the surface and not to some other source. There are several cases where adsorbed gases cause rearrangement of the surface atoms in the adsorbent substrate. 1,12,1 3 When adsorbed gases cause rearrangement, the resulting diffraction pattern is bright, sharp, and distinct, as are those from a clean surface; whereas, a diffraction pattern caused by a gas layer on a surface is $\operatorname{dim}$ and diffuse.14,15 Also, when rearrangement occurs, it is unaffected by additional exposure to the adsorbing gas. Since the patterns observed here are diffuse and are altered by additional exposure, they are assumed to be caused by adsorbed nitrogen on the tungsten surface.

Allhough the inner square structure can be explained by a half-monolayer of nitrogen atoms as argued above, further argument is necessary to show that this is indeed the case. On the (100) plane of a tungsten crystal there is one tungsten atom in an area $3.16469 \AA$ square. Thus, there are $10^{15}$ tungsten atoms per square centimeter on this plane. Assuming that il is possible for one nitrogen atom to adsorb for every tungsten surface atom, ${ }^{16}$ then $10^{15}$ atoms or $5 \times 10^{14}$ molecules of nitrogen would form a monolayer on one square centimeter of surface. Thus, a half-monolayer would contain $2.5 \times 10^{14}$ molecules per square centimeter. 


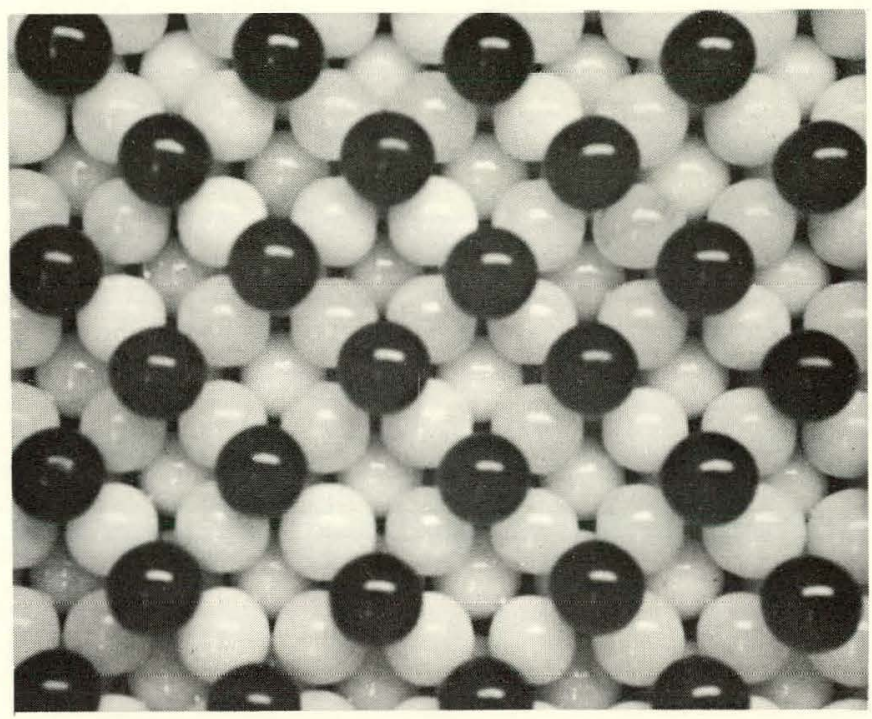

Figure 11. MARBLE MODEL OF THE HALF-MONOLAYER NITROGEN COVERAGE. THE WHITE MARBLES INDICATE THE POSITIONS OF THE TUNGSTEN ATOMS AND THE BLACK MARBLES INDICATE THE POSITIONS OF THE NITROGEN ATOMS. 
From kinetic theory it is known that $3.75 \times 10^{20}$ nitrogen molecules strike one square centimeter each second at 1 torr pressure. Thus, during an exposure of $5 \times 10^{-6}$ torr-sec, $1.875 \times 10^{15}$ nitrogen molecules would strike one square centimeter. Not every molecule that strikes a surface sticks. The ratio of the number of molecules which stick to the number that strike is the sticking probability. Delchar and Ehrlich ${ }^{7}$ report an initial sticking probability for nitrogen on (100) tungsten of approximately 0.1 . When nitrogen is adsorbed on tungsten, the sticking probability decreases slightly from its initial value as adsorption progresses until the si face is approximately half covered. Then it decreases more rapidly to very small values near total monolayer coverage.18 Assuming that the sticking probability remained constant at the initial value of 0.1 during an exposure of $5 \times 10^{-6}$ torr-sec, $1.875 \times 10^{14}$ molecules or $3.75 \times 10^{14}$ atoms would stick to a tungsten (100) surface. Considering the errors in measuring the exposures and intensities and that the value 0.1 for the sticking probability is somewhat low, this value compares favorably with that for half-monolayer coverage.

As the adsorption continues, the empty sites on the tungsten gradually fill up, but with decreasing sticking probability. When a complete monolayer is formed, there is one adsorbed nitrogen atom for every tungsten surface atom. It is logical to assume that the adsorbed atoms will form in a regular manner since the surface on which they form is regular. The simplest and most favorable arrangement is that shown in Figure 12. The nitrogen atoms form in a regular array with an overall pattern identical to that of the tungsten surface. 


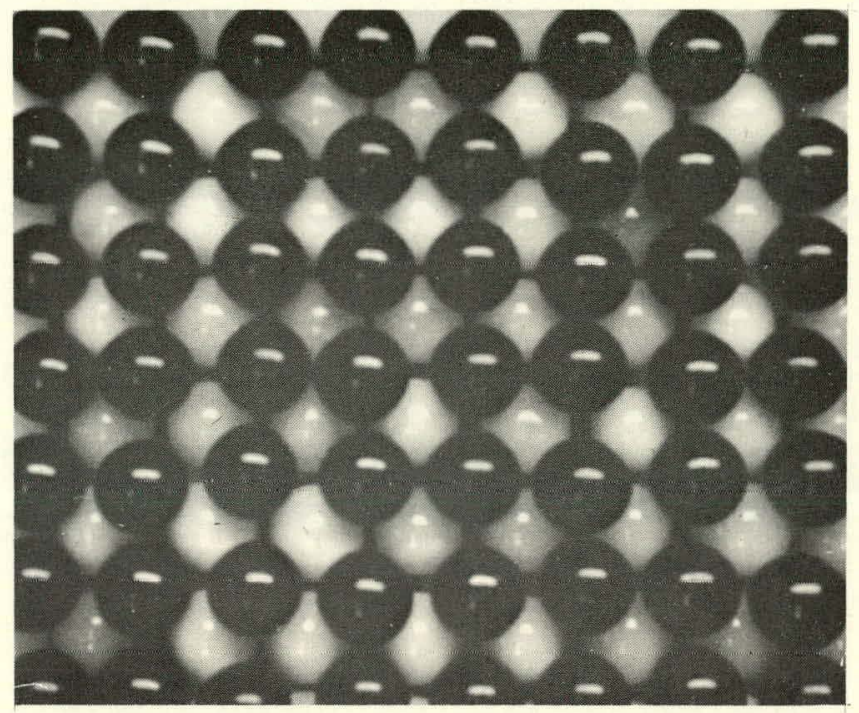

Figure 12. MARBLE MODEL OF THE MONOLAYER NITROGEN COVERAGE. THE BLACK MARBLES REPRESENT NITROGEN ATOM POSITION AND THE WHITE REPRESENT THE TUNGSTEN ATOMS. 
The diffraction pattern expected from an arrangement like Figure 12 would be similar to that from a clean surface, since the spacing of the chemisorbed nitrogen atoms is the same as that of the tungsten substrate. The background intensity would increase because the gas atoms do not scatter the electrons as effectively as do the metal atoms. There is also a possibility of scattering in the [10] directions due to nitrogen atoms, since there is only a single layer and thus no destructive interference from a lower gas layer. This type of pattern is observed and can be seen in Figure 10d.

Nitrogen adsorption on a tungsten (100) surface as observed in this LEED study can be summarized as follows: Adsorption proceeds rapidly in preferred sites until a half-monolayer is formed with each nitrogen atom bound to two tungsten surface atoms. The rate of adsorption then decreases as the surface coverage increases. Finally, a monolayer is formed with one nitrogen atom adsorbed for each tungsten surface atom and with a structure identical to that of the substrate.

\section{Hydrogen Chemisorption}

Hydrogen was adsorbed on the clean crystal surface at room temperature following the same procedure that was used for nitrogen. The diffraction patterns observed as the adsorption progressed are shown in Figure 13. At $77 \mathrm{~V}$ the change from the clean surface pattern is the occurrence of dim, diffuse spots in the [10] directions. The spots increase in intensity as adsorption proceeds to a maximum, after which the relative intensity of the spots appears to remain the same. After they reach the maximum at about 


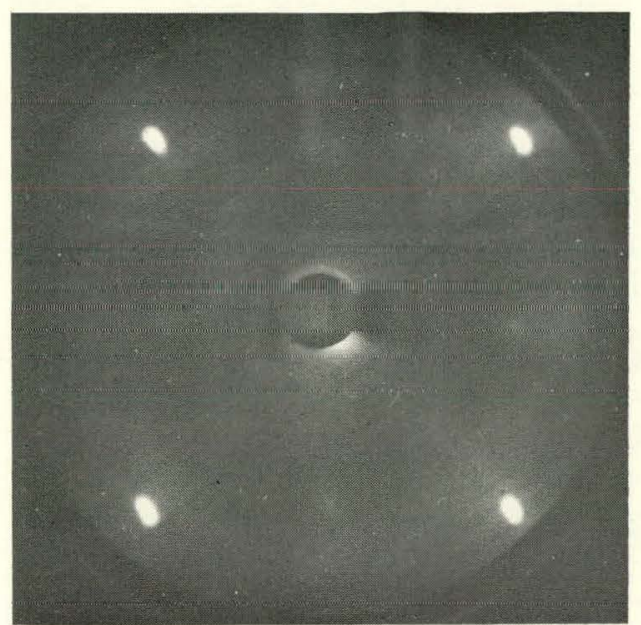

(a)

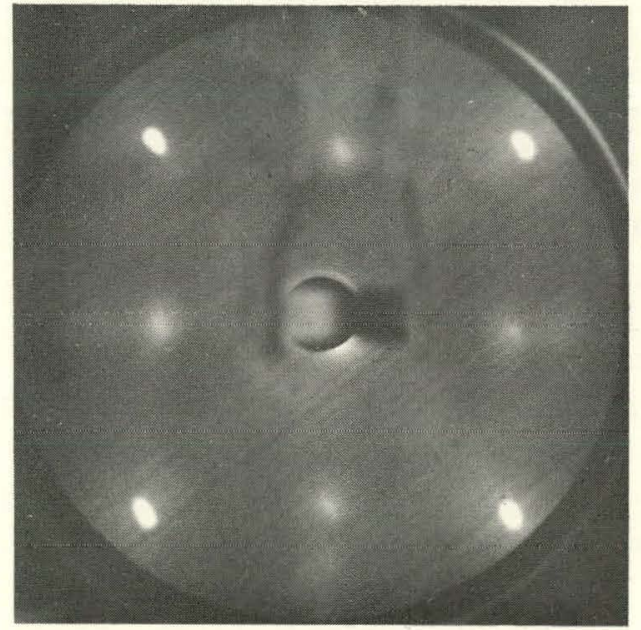

(c)

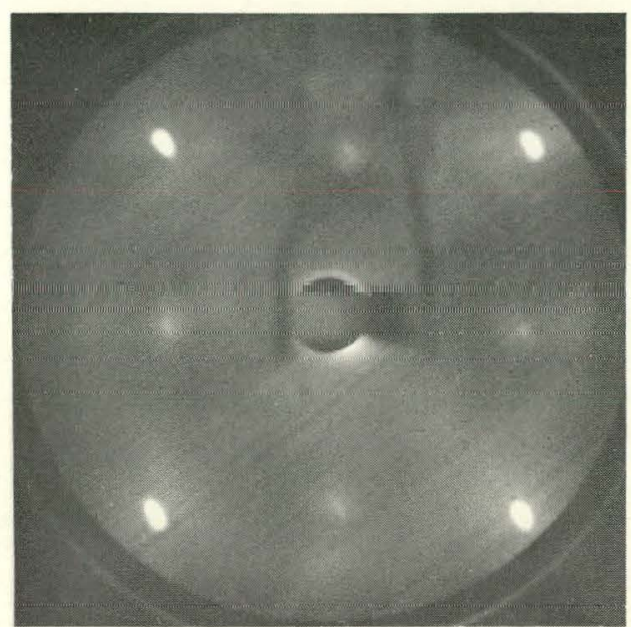

(b)

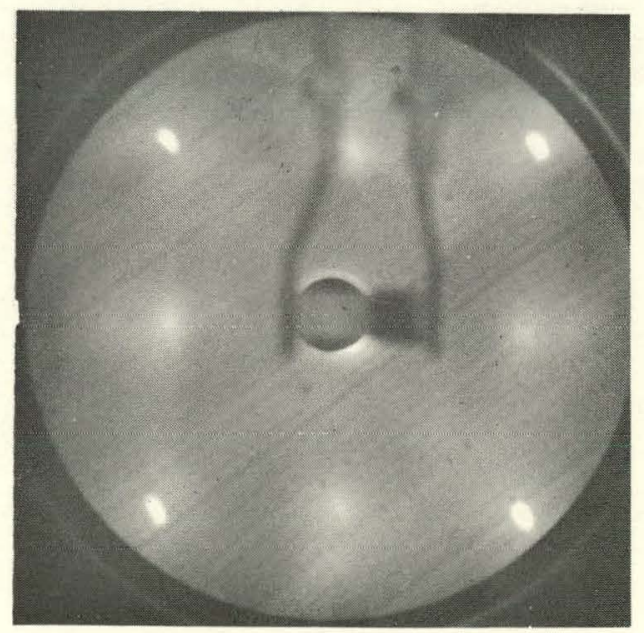

(d)

Figure 13. DIFFRACTION PATTERNS AT 77V FOR HYDROGEN:

(a) AFTER AN EXPOSURE OF $2.5 \times 10^{-6}$ TORR-SEC, (b) AFTER AN EXPOSURE OF $5 \times 10^{-6}$ TORR-SEC, (c) AFTER AN EXPOSURE OF $5 \times 10^{-5}$ TORR-SEC AND (d) AFTER AN EXPOSURE OF $1.5 \times 10^{-4}$ TORR-SEC 
$1.5 \times 10^{-5}$ torr-sec exposure, the only change in the pattern is an overall increase in the background intensity.

During an exposure of $1.5 \times 10^{-5}$ torr-sec, $5.6 \times 10^{15}$ molecules strike a square centimeter of surface. Eisinger has reported a sticking probability for hydrogen on tungsten of 0.2 for coverages less than $4 \times 10^{14}$ atoms per square centimeter. ${ }^{19}$ Assuming $10^{15}$ sites per square centimeter, a monolayer of hydrogen or nearly a monolayer would be formed during this exposure.

The diffraction spots occur at positions in the [10] directions indicative of a spacing equal to that of the tungsten substrate lattice. The amount of hydrogen adsorbed, measured by flashing the crystal, was approximately $6 \times 10^{14}$ molecules per square centimeter. This is approximately one hydrogen atom per tungsten surface atom. Thus it appears that a monolayer of hydrogen forms on the tungsten (100) face in a manner shown in Figure 12. The hydrogen atoms adsorb at sites in the center of the square formed by four equally spaced tungsten atoms.

\section{Carbon Monoxide Chemisorption}

The diffraction patterns obtained during carbon monoxide adsorption at room temperature after various exposures are shown in Figure 14. The distinguishing feature of the gas-covered surface pattern is the occurrence of very diffuse bright areas in the [10] directions. The lattice spacing necessary to cause these bright areas in the observed position is one which is equal to the interatomic spacing of the tungsten crystal in the [10] directions. 


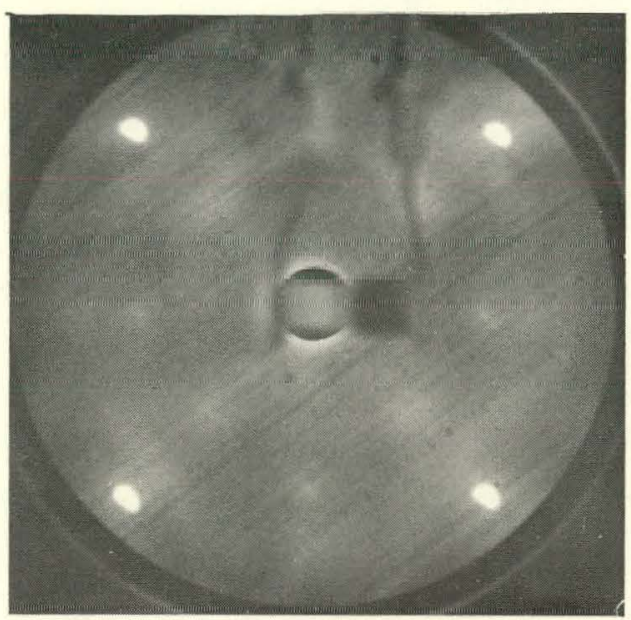

(a)

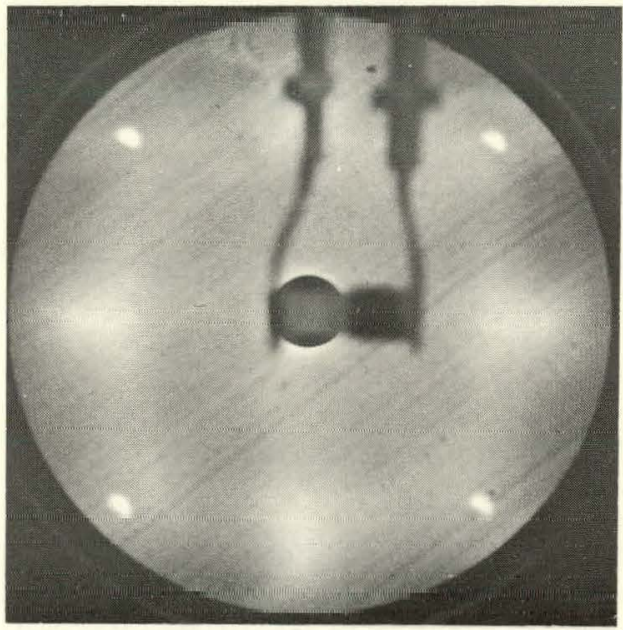

(c)

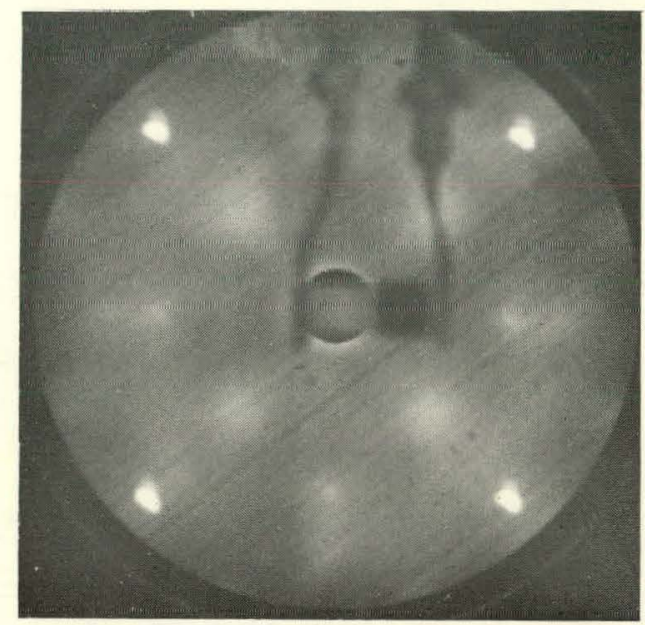

(b)

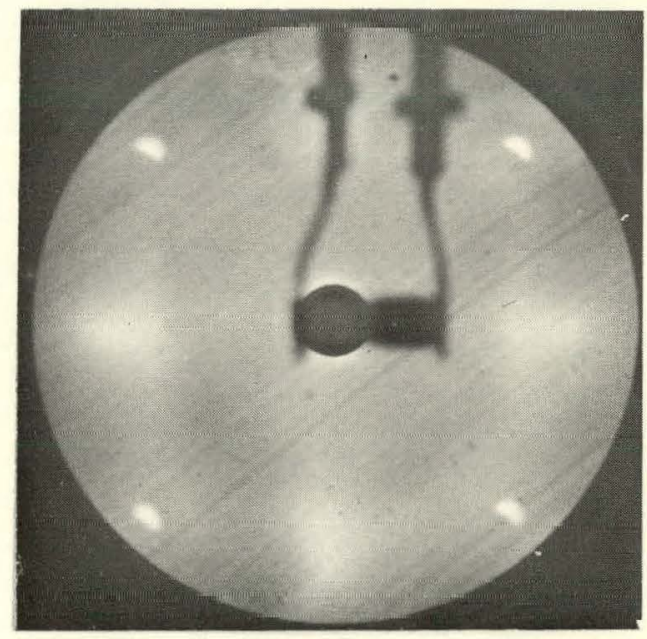

(d)

Figure 14. DIFFRACTION PATTERNS AT 77V FOR CARBON MONOXIDE ADSORPTION :

(a) $2.5 \times 10^{-6}$ TORR-SEC

EXPOSURE, (b) $5 \times 10^{-6}$ TORR-SEC EXPOSURE, (c) $5 \times 10^{-5}$ TORR-SEC EXPOSURE AND (d) $1.5 \times 10^{-4}$ TORR-SEC EXPOSURE 
A similarity between the carbon monoxide pattern and the hydrogen pattern can be noticed. The spots occur in the same positions in the [10] directions, and they build up to maximum and remain unchanged during continued exposure. However, the carbon monoxide pattern is much more diffuse than is the hydrogen pattern. This is probably due to the hydrogen penetrating somewhat into the tungsten lattice, while the carbon monoxide sits on the surface with very little if any penetration. Also, the carbon monoxide is adsorbed as a molecule, ${ }^{20}$ whereas hydrogen dissociates and is adsorbed as atomic hydrogen. ${ }^{21}$ More diffraction could thus be expected from the carbon monoxide than from the hydrogen, causing a brighter pattern for the carbon monoxide. The more localized hydrogen would give a more distinct spot than would the larger carbon monoxide.

\section{Oxygen Chemisorption}

After the crystal was heated to $2100^{\circ} \mathrm{C}$ and cooled to room temperature, pure oxygen was admitted to the chamber to pressures of $5 \times 10^{-9}$ to $5 \times 10^{-6}$ torr. Figure 15 shows the diffraction results for the oxygen adsorption after various exposures.

Significant changes are observed in the $77 \mathrm{~V}$ pattern as oxygen is adsorbed. Figure $15 \mathrm{a}$ is the clean surface pattern for $77 \mathrm{~V}$ electrons. The pattern consists of four equally intense, well defined spots in the [11] directions, forming the corners of a square. After an exposure of $1.5 \times 10^{-6}$ torr-sec, the pattern shown in Figure $15 \mathrm{~b}$ becomes visible. (Figure 15b is the pattern after $2.5 \times 10^{-6}$ torr-sec exposure to oxygen when the pattern reaches its maximum intensity.) The spots in the [11] directions 


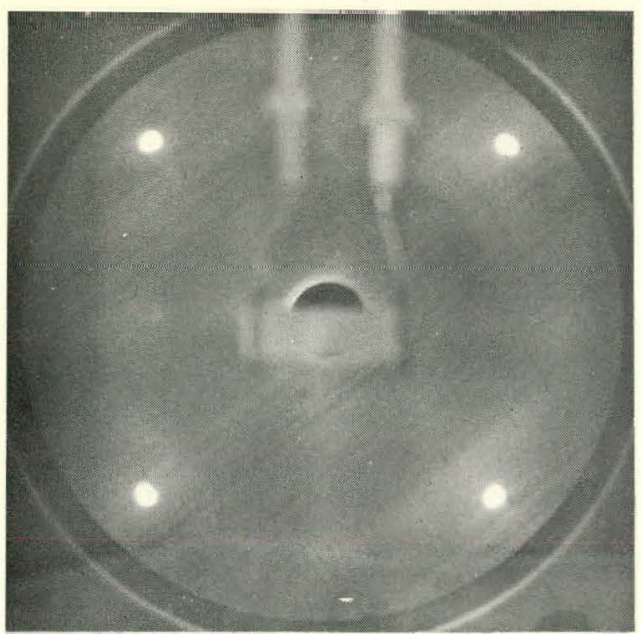

(a)

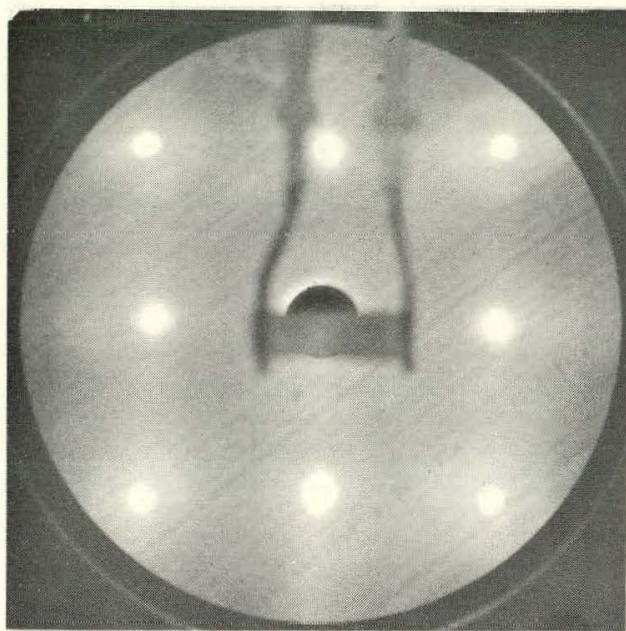

(c)

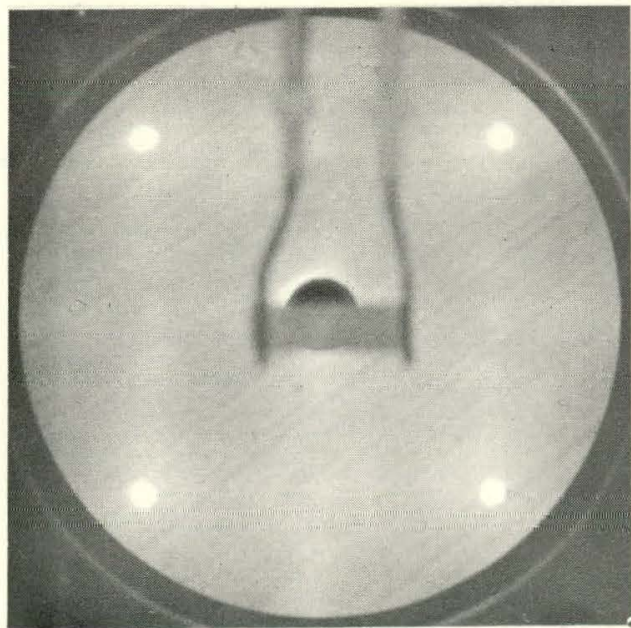

(e)

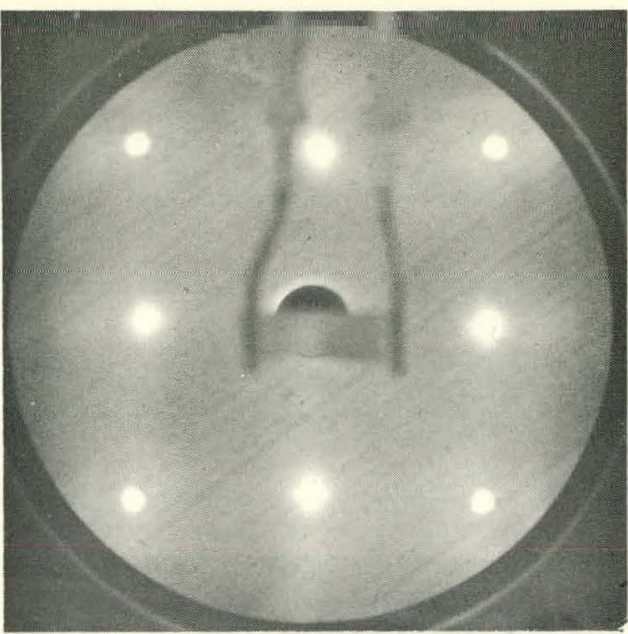

(b)

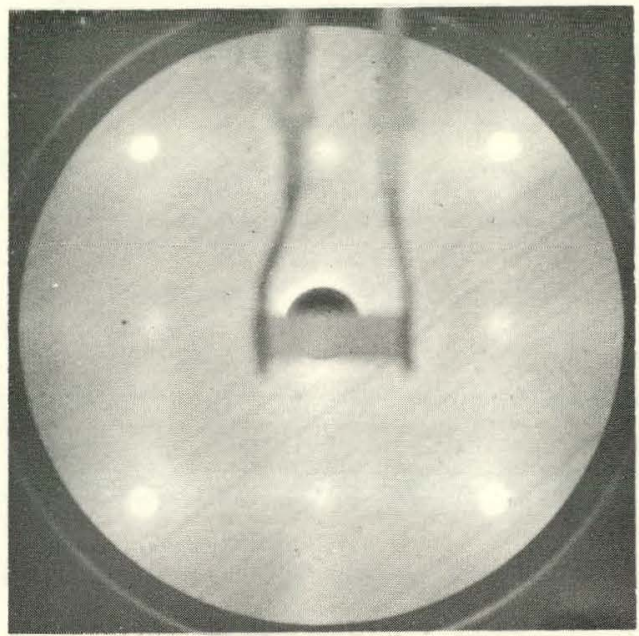

(d)

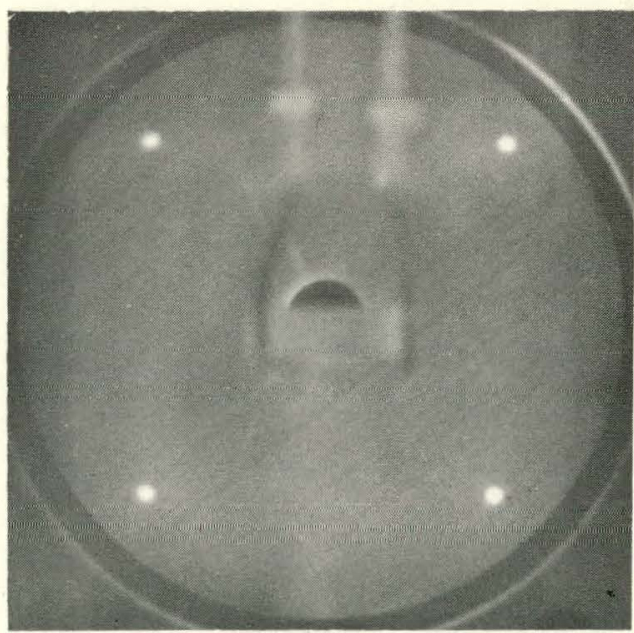

(f)

Figure 15. DIFFRACTION PATTERN AT 77V SHOWING OXYGEN ADSORPTION: (a) CLEAN SURFACE, AFTER AN EXPOSURE OF (b) $2.5 \times 10^{-c}$ TORR-SEC, (c) $5 \times 10^{-6}$ TORR-SEC, (d) $5 \times 10^{-5}$ TORR-SEC, (e) $1.5 \times 10^{-4}$ TORR-SEC AND (f) AFTER SEVERAL HOURS EXPOSURE AT $1 \times 10^{-8}$ TORR 
in this pattern are still well defined and are of approximately the same intensity and in the same position as for a clean surface. The pattern that appears to be due to the oxygen consists of the four bright spots in the [10] directions at the midpoint of the sides of the square.

Figure $15 \mathrm{c}$ shows the pattern observed after an exposure of $5 \times 10^{-6}$ torrsec. This pattern is like that shown in Figure 15b except for a slight diminution in the intensity nf the spots in tho [10] dircctions. Continual exposure to oxygen causes a further decrease in the intensity of the [10] spots, as is seen in Figure 15d taken after a $5 \times 10^{-5}$ torr-sec exposure, until they finally disappear. The [10] spots disappear after an exposure of about $1.5 \times 10^{-4}$ torr-sec (Figure 15e). With continued oxygen exposure, the only change in the diffraction pattern is a decrease in the intensity of the spots due to the tungsten surface. Figure $15 f$ shows the pattern after several hours exposure to oxygen at $1 \times 10^{-8}$ torr. The pattern is identical in structure with the clean surface pattern exccpt for a decrease in spot intensity and an overall increase in background intensity.

The four spots which appear upon oxygen adsorption occur at angles of $26^{\circ}$ in the [10] directinns. Applying the Lauc condition, $\mathrm{n} \lambda-\mathrm{d} s \mathrm{~s}$ - $\theta$, an angle of this magnitude would correspond to a spacing of $3.16 \AA$, assuming first order diffraction, $\mathrm{n}=1$. If second order diffraction, $\mathrm{n}=2$, is considered, d would equal $6.32 \AA$. The interatomic distance for a tungsten crystal is $3.16 \AA$ and is thus the spacing between rows and columns in the [10] directions. The pattern observed due to oxygen adsorption is essentially that which would be expected from a clean surface, barring interference from lower layers. Thus, it might be expected that the oxygen causes sufficier rearrangement of the tungsten atoms to eliminate this interference. 
Another explanation would be that the oxygen atoms assume positions which enhance the scattering in the [10] directions or cause constructive interference in those directions. A third explanation is that the oxygen atoms are arranged in rows and columns with twice the tungsten lattice spacing. It is necessary to use second order diffraction to explain the observed pattern in this third case.

In order to determine which of these three alternatives best describes the observed adsorption process for the oxygen, let us review the observations. First, a strong diffraction pattern in the [10] directions at $77 \mathrm{~V}$ appears fairly rapidly and then disappears slowly. Second, this effect is not observable at higher electron energies. Third, little if any change is observed in the [11] directions in the $44 \mathrm{~V}$ pattern. And last, about twice the amount of gas is adsorbed after an exposure of $1.5 \times 10^{-4}$ torr-sec.as after an exposure of $1.5 \times 10^{-6}$ torr-sec.

Since the pattern is not observed at higher electron energies where there is deeper penetration, no significant rearrangement of the tungsten surface atoms is likely. Also, the absence of a change in the higher energy patterns indicates that the pattern is due to the adsorbed gas atom rather than to the tungsten atoms. If a significant rearrangement of the tungsten atoms took place, changes in the pattern due to this rearrangement would be prominent at higher electron energies. A rearrangement would also cause a change in the basic square structure observed in the [11] directions at 77V. This is not observed. In fact, the clean surface pattern is observed to remain tact throughout the entire adsorption process. The evidence indicates that no significant rearrangement of atoms at the surface of the tungsten crystal takes place. 
If the oxygen atoms were adsorbed at sites surrounded by four tungsten surface atoms, they would form a pattern of rows and columns in the [10] directions with a spacing of twice the tungsten lattice spacing. Such an arrangement would give diffraction spots at approximately $13^{\circ}$ in the [10] directions at $77 \mathrm{~V}$ for $\mathrm{n}=1$, i.e., in the first order. Second order diffraction, $\mathrm{n}=2$, would place diffraction spots at about $26^{\circ}$ in the [10] directions. The diffraction spots in question occur at approximately $26^{\circ}$ in the [10] directions, with nothing observed at $13^{\circ}$. Since there is no source of interference to cancel the first order diffraction, this explanation seems unlikely.

The most plausible explanation appears to be that the oxygen atoms adsorb in all the available interstitial positions with a fairly high sticking probability. After all these sites are filled (the condition shown in Figure 12), a second layer forms with a very small sticking probability and lower binding energy. : The small size of the oxygen atom allows it to fit casily but snugly into the interstitial positions on the surface. Thus, it would be tightly bound by covalent bonds to the five nearest tungsten atoms, four in the surface layer and one in the second layer. Oxygen atoms in the interstitial sites will change the scattering characteristics by altering the phase differencences in the [10] directions between electrons scattered from the top and second layers. Since the interstitial sitco lie along the rows in the [11] directions, we would expect little effect in these directions.

The pattern in question reaches its maximum intensity after an exposure of approximately $2.5 \times 10^{-6}$ torr-sec. During this exposure, $1.875 \times 10^{15} a t_{1}$ strike one square centimeter of area. To form a complete monolayer during 
this exposure, an average sticking probability of 0.53 is required, which is not unreasonable. There are no measurements of sticking probability for oxygen on a tungsten (100) surface in the literature. None could be made during these experiments because the apparatus is not constructed properly for such measurements. However, George and Stier report an initial sticking probability at $300^{\circ} \mathrm{K}$ of 0.8 for oxygen on a field-emission microscope with a tip made of tungsten, ${ }^{22}$ and schlier reports 0.65 for a polycrystalline ribbon. ${ }^{23}$ Thus, a value of 0.5 is not unreasonable.

Additional oxygen is adsorbed slowly with an average sticking probability of about 0.009. The oxygen atoms forming this second layer adsorb on top of the tightly bound atoms in the first layer. The atoms in the first layer are undoubtedly influenced by the additional oxygen which could possibly cause a change in their positions. If the additional oxygen, i.e., the second layer, forms a more or less amorphous layer, it would cause a washout of the diffraction pattern due to the first layer. The overail background intensity would increase and the intensity of the spots associated with the tungsten surface would decrease. This is the sort of thing which is observed.

Thus, it is felt that oxygen forms a monolayer on a tungsten (100) surface rapidly by filling all the available interstitial sites. After these sites are filled, a second layer forms over the entire surface in a more weakly bound state. It was observed that the [10] pattern could be reinstated after long exposure to oxygen by heating the crystal to about $1000^{\circ} \mathrm{C}$ for a s? seconds. 
RFP-643

44 


\section{LITERATURE REFERENCES}

1. J. J. Lander and J. Morrison, J. Chem. Phys. 37, 729 (1962).

2. J. J. Lander and J. Morrison, J. Appl. Phys. 34, 1403 (1963).

3. J. J. Lander and J. Morrison, J. App1. Phys. 34, 1411 (1963).

4. L. H. Germer, A. U. MacRae, and C. D. Hartman, J. Appl. Phys. 32 , 2432 (1961).

5. L. H. Germer and A. U. MacRae, J. Chem. Phys. 37, 1382 (1962).

6. Varian Associates, Vacuum Products Division, Palo Alto, California.

7. W. Ehrenberg, Phil. Mag. 18, 878 (1934).

8. E. J. Scheibner, L. H. Germer, and C. D. Hartman, Rev. Sci. Instr. 31,112 (1960).

9. L. H. Germer and C. D. Hartman, Rev. Sci. Instr. 31, 784 (1960).

10. J. J. Lander, J. Mórison, and F. Unterwald, Rev. Sci. Instr. 33, 782 (1962):

11. Single Crystal Division, Semi-Elements Inc., Saxonburg, Pennsylvania.

12. L. H. Germer and C. D. Hartman, J. Appl. Phys. 31, 2085 (1960) .

13. L. H. Germer and A. U. MacRae, J. Appl. Phys. 33, 2923 (1962).

14. L. H. Germer, E. J. Scheibner, and C. D. Hartman, Phil. Mag. , 222 (1960).

15. L. H. Germer and A. U. MacRae, Proc. Natl. Acad. Sci. U.S. 48, 997 (1962).

16. P. Kisliuk, J. Chem. Phys. 30, 174 (1959).

7. T. A. Delchar and G. Ehrlich, J. Chem. Phys. 42, 2686 (1965). 
18. L. J. Rigby, Can. J. Phys. 43, 532 (1965).

19. J. Eisinger, J. Chem. Phys. 29, 1154 (1958) .

20. T. W. Hickmott and G. Ehrlich, J. Chem. Phys. 24, 1263 (1956).

21. T. W. Hickmott, J. Chem. Phys. 32, 810 (1960).

22. T. H. George and P. M. Stier, J. Chem. Phys. 37, 1935 (1962).

23. R. E. Schlier, J. Appl Phys. 29, 1162 (1958). 